\title{
The case for low dose diuretics in hypertension: comparison of low and conventional doses of cyclopenthiazide
}

\author{
Gary McVeigh, David Galloway, Dennis Johnston
}

\begin{abstract}
In a double blind placebo controlled randomised parallel study the antihypertensive activity and adverse biochemical effects of three doses of cyclopenthiazide were evaluated in patients with mild essential hypertension that had been recently diagnosed or was being treated with a single drug. After a four week placebo washout period 53 patients with diastolic blood pressures between $90-110 \mathrm{~mm}$ $\mathrm{Hg}$ were randomly assigned to 50,125 , or $500 \mu \mathrm{g}$ cyclopenthiazide or matching placebo for an eight week period of treatment. Blood pressure was measured in the patients' homes by the same observer every two weeks. Serum urea, electrolytes, urate, and creatinine concentrations and 24 hour urinary sodium excretion were monitored every four weeks and serum magnesium concentration and plasma renin activity at the end of the washout and treatment periods. After eight weeks of treatment systolic and diastolic blood pressures were significantly reduced in patients taking 125 and $500 \mu \mathrm{g}$ cyclopenthiazide when compared with those taking placebo. The decrement in serum potassium concentration $(0.6$ $\mathrm{mmol} / \mathrm{l}$ ) and increase in serum urate concentration $(0.06 \mathrm{mmol} / \mathrm{l})$ were greatest with the $500 \mu \mathrm{g}$ dose, the increase in serum urate concentration alone being significant. No change in serum magnesium concentration or 24 hour urinary sodium excretion was noted with any dose of cyclopenthiazide. Only the $500 \mu \mathrm{g}$ dose of cyclopenthiazide significantly increased the mean plasma renin activity $(1.8(95 \%$ confidence interval 0.2 to 3.4$)-5.4(3.9$ to 6.8$) \mathrm{nmol}$ angiotensin $\mathrm{I} / \mathrm{l} / \mathrm{h}$ ); the other doses like the placebo had no effect.

Cyclopenthiazide $125 \mu \mathrm{g}$, a dose lower than is currently marketed, produced a similar hypotensive response to $500 \mu \mathrm{g}$ of the drug without upsetting the biochemical profile.
\end{abstract}

\section{Introduction}

Benzothiadiazine diuretics have remained a popular treatment for arterial hypertension since their introduction into clinical practice in $1957 . .^{1}$ They are a cheap, effective, well tolerated, and once daily treatment and in combination potentiate the hypotensive activity of other first line agents. All the large scale clinical trials of mild hypertension have used thiazide diuretics as part of their treatment regimens. . $^{2-5}$ Analysis of these studies confirms a small but consistent benefit of treatment, with a reduction in the incidence of known complications of hypertension.

The antihypertensive mechanism of action of these drugs is still debatable, although achieving a negative sodium balance with an attendant reduction in plasma and extracellular fluid volume seems to be important. ${ }^{6}$ Perhaps for this reason most clinical trials continue to use high doses of diuretic drugs to control essential hypertension. The original observations of Cranston et al clearly indicated, however, that these drugs showed a flat dose-response relation in reducing arterial blood pressure and that increased doses caused greater upset to the biochemical profile. ${ }^{7}$ Equivalent diuretic doses of each of the drugs had similar antihypertensive effects. Much evidence suggests that the attenuation of the hypotensive response to an increasing dose of diuretic is mediated through a reactive rise in plasma renin activity and angiotensin II concentration to try to maintain blood pressure in the face of increased sodium and water depletion. ${ }^{8-10}$

Many deleterious metabolic effects have been associated with the use of thiazide diuretics. "12 The relation with hypokalaemia in particular has provoked much debate since publication of the results of the multiple risk factor intervention trial. ${ }^{13}$ Analysis of the data suggested that a subgroup of patients requiring special intervention care were at increased risk of sudden death; such patients were taking high doses of diuretics and had minor baseline electrocardiographic abnormalities. These findings continue to cause concern, even though they have not been substantiated ${ }^{14}$ and are questionable because the analysis of the results for the subgroup lacked statistical power. ${ }^{15}$ The results of the previous studies suggest that the adverse effects may be minimised by reducing the dose of these drugs. ${ }^{1617}$

Cyclopenthiazide is the most popular thiazide diuretic for the treatment of essential hypertension in the United Kingdom. The aims of this community based study were to define the lowest dose of drug showing significant antihypertensive activity and to monitor the effect of reducing the dose on the metabolic profile. In addition, in measuring 24 hour urinary excretion of sodium we tried to relate the natriuretic effect of the various doses to their antihypertensive efficacy.

\section{Patients and methods}

Patients in whom hypertension had been newly diagnosed and those with hypertension receiving a single treatment-for example, a $\beta$ blocker, thiazide diuretic, calcium antagonist, and so on-who were willing to alter their treatment for the purposes of the trial were recruited from general practices in the Belfast area. With the general practitioners' permission patients with hypertension were identified from repeat prescription books and disease indices or referred directly after consultation with their family doctor. Letters were then circulated to each patient explaining the nature of the project. If patients were willing to participate in the study an acknowledgement slip was returned in the stamped-addressed envelope provided. These patients were screened in the department of therapeutics and the study protocol was explained in detail. Possible secondary causes of hypertension were 
excluded by a full history and examination, which included chest radiography and electrocardiography. Reasons for exclusion from the study included important cardiac, hepatic, renal, cerebrovascular, or ocular (grade III-IV retinopathy) disease; previous sensitivity to thiazide diuretics; abuse of drugs or alcohol; and a history of gout or diabetes mellitus. If at any time during the trial the diastolic blood pressure exceeded $110 \mathrm{~mm}$ $\mathrm{Hg}$ the patient's original treatment was restarted and his or her general practitioner contacted. Informed verbal consent was obtained from suitable patients who entered into a four week single blind placebo washout and compliance period.

Throughout the trial patients were seen in their own homes every two weeks by the same investigator. Blood pressure readings were taken at the same time of day, for each patient, on every occasion. Recordings were taken from both arms initially, but subsequent measurements were taken from the arm with the highest diastolic pressure. A Hawksley random zero sphygmomanometer was used to measure arterial pressure to the nearest $2 \mathrm{~mm} \mathrm{Hg}$. The cuff and bladder size were $14 \times 90$ $\mathrm{cm}$ and $12 \cdot 5 \times 22 \mathrm{~cm}$, respectively. Readings were taken once only while the patients were seated and after they had rested for 10 minutes. The arm was supported at the level of the heart during the procedure ${ }^{18}$ Disappearance of the Korotkoff sounds (phase V) was taken as a measure of diastolic blood pressure. The arterial pressure reading against which the effects of treatment

TABLE I-Clinical data on patients who completed trial

\begin{tabular}{lccccc}
\hline & & \multicolumn{3}{c}{ Dose of cyclopenthiazide $(\mu \mathrm{g})$} & \\
\cline { 3 - 5 } & Placebo & 50 & 125 & 500 & Total \\
\hline No of patients & 12 & 13 & 15 & 13 & 53 \\
No of men & 7 & 5 & 5 & 5 & 22 \\
No of women & 5 & 8 & 10 & 8 & 31 \\
Mean age (range) (years) & $58(47-70)$ & $59(47-70)$ & $56(45-73)$ & $55(45-72)$ & $57(45-73)$ \\
Mean (SD) weight (kg): & $75(5 \cdot 8)$ & $81(5 \cdot 8)$ & $77(5 \cdot 8)$ & $72(5 \cdot 2)$ & $76(5 \cdot 8)$ \\
$\quad$ Men & $71(5 \cdot 4)$ & $66(4 \cdot 9)$ & $70(5 \cdot 3)$ & $66(4 \cdot 8)$ & $68(5 \cdot 2)$ \\
Women & & & & & \\
\hline
\end{tabular}

TABLE II-Mean (SD) sitting blood pressure $(\mathrm{mm} \mathrm{Hg}$ ) at each assessment by dose of cyclopenthiazide

\begin{tabular}{|c|c|c|c|c|c|c|c|c|}
\hline \multirow{3}{*}{$\begin{array}{l}\text { Assessment } \\
\text { (weeks) }\end{array}$} & & & \multicolumn{6}{|c|}{ Dose of cyclopenthiazide $(\mu \mathrm{g})$} \\
\hline & \multicolumn{2}{|c|}{ Placebo $(n=12)$} & \multicolumn{2}{|c|}{$50(n=13)$} & \multicolumn{2}{|c|}{$125(n=15)$} & \multicolumn{2}{|c|}{$500(n=13)$} \\
\hline & Systolic & Diastolic & Systolic & Diastolic & Systolic & Diastolic & Systolic & Diastolic \\
\hline 0 & $157(17)$ & $94(3)$ & $167(19)$ & $99(3)$ & $169(23)$ & $99(6)$ & $164(18)$ & $95(4)$ \\
\hline 2 & $155(16)$ & $92(6)$ & $161(20)$ & $97(6)$ & $155(18)$ & $90(7)$ & $152(16)$ & $88(5)$ \\
\hline 4 & $155(20)$ & $94(5)$ & $163(21)$ & $96(4)$ & $157(17)$ & $91(7)$ & $152(18)$ & $89(8)$ \\
\hline 6 & $155(16)$ & $93(4)$ & $158(21)$ & $96(5)$ & $158(23)$ & $90(7)$ & $149(19)$ & $88(9)$ \\
\hline 8 & $156(17)$ & $93(5)$ & $159(19)$ & $94(7)$ & $149(22)^{\star}$ & $88(9)^{\star}$ & $140(20)^{\star}$ & $85(8)^{\star}$ \\
\hline
\end{tabular}

${ }^{\star} \mathrm{p}<0.05$ as compared with placebo.

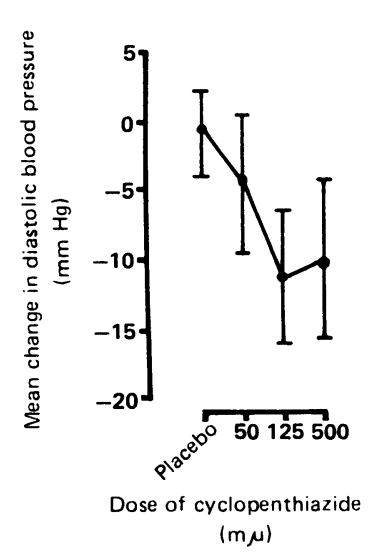

Dose-response effect of cyclopenthiazide on diastolic pressure on completion of eight weeks of active treatment. Vertical bars indicate $95 \%$ confidence intervals venous blood samples were taken for estimating urea, electrolyte, urate, and creatinine concentrations. At the end of the placebo washout and active periods of treatment, samples of venous blood were taken for estimating serum magnesium concentration and plasma renin activity. The sample for plasma renin activity was withdrawn after the patient had been resting supine for an hour. It was collected in a tube that had been previously cooled and was immediately centrifuged at $4^{\circ} \mathrm{C}$. Plasma renin activity was measured by the radioimmunoassay of generated angiotensin $\mathrm{I}$, with a generation time of 90 minutes at $\mathrm{pH} 6 .{ }^{19}$ The intra-assay and interassay coefficients of variation were 7 and $6 \%$, respectively. Twenty four hour urine samples were collected every four weeks during the trial, and the sodium content of the samples was estimated by flame photometry.

Statistical methods-A $10 \mathrm{~mm} \mathrm{Hg}$ drop in diastolic blood pressure with treatment was considered to be a clinically relevant effect. To detect such a difference between groups (at the 5\% alpha level and with $80 \%$ power) with a standard deviation of $5 \mathrm{~mm} \mathrm{Hg}$, six or more patients were required in each group..$^{20} \mathrm{An}$ analysis of variance (Anova) was used to determine differences with treatment in each variable, and Neuman-Keuls multiple range test ${ }^{21}$ was applied to determine between which treatments these occurred only if the overall probability of an effect with dose was less than $10 \%$. The level of significance was chosen at the $5 \%$ level. The differences between the values at week 0 (end of the run in period) and week 8 (end of the active period of treatment) were compared with the differences between the corresponding values for the placebo at weeks 0 and 8. Results are expressed as means (SD).

\section{Results}

Eighty three patients with presumed mild essential hypertension entered the study, and 53 fulfilled the criteria for entry into the active phase of treatment of the trial. This represented a drop out rate of $36 \%$ overall. Twenty two patients were found to be normotensive (diastolic blood pressure $<90 \mathrm{~mm} \mathrm{Hg}$ ) at the end of the four week placebo washout period. Of the remaining eight patients who withdrew from the study, three were unable to tolerate the placebo, two were admitted to hospital with low back pain, and one developed unacceptable ankle oedema. The blood pressure exceeded $240 \mathrm{~mm} \mathrm{Hg}$ systolic in one patient and $110 \mathrm{~mm} \mathrm{Hg}$ diastolic in another so the original treatment was restarted. Table I shows the clinical data on the patients who completed the study. The 31 women and 22 men were similar for age and weight.

Table II shows the effect on blood pressure of the various doses of cyclopenthiazide. After eight weeks of treatment both systolic and diastolic blood pressure fell significantly $(p<0.05)$ in patients taking 125 and $500 \mu \mathrm{g}$ of cyclopenthiazide when compared with those taking placebo. The decrements in blood pressure produced by the two doses were not significantly different from each other. The hypotensive effect was evident by two weeks and maximal after eight weeks of treatment. The $50 \mu \mathrm{g}$ preparation showed no useful antihypertensive activity. The figure shows the change in diastolic blood pressure plotted against dose of cyclopenthiazide after eight weeks of treatment; a similar curve was found for systolic blood pressure.

No significant change in body weight or packed cell volume was noted with any dose of cyclopenthiazide during the trial. The $500 \mu \mathrm{g}$ dose produced a greater reduction in serum potassium concentration $(0.6$ $\mathrm{mmol} / \mathrm{l}$ ) than the other doses. The effect of the drug on serum urate concentration with the $500 \mu \mathrm{g}$ dose was 
significantly different from that produced by the 50 and $125 \mu \mathrm{g}$ doses after eight weeks of treatment $(\mathrm{p}<0.05)$ (table III). No dose related effects on serum magnesium concentration or 24 hour urinary sodium excretion were found during the study. The mean plasma renin activity increased from $1.8(95 \%$ confidence interval 0.2 to 3.4$)$ to $5 \cdot 4(3.9$ to 6.8$) \mathrm{nmol}$ angiotensin $\mathrm{I} / \mathrm{l} / \mathrm{h}$ with the $500 \mu \mathrm{g}$ dose of cyclopenthiazide (table IV). This change was significantly different from that with the 50 and $125 \mu \mathrm{g}$ doses $(\mathrm{p}<0.05)$.

Table $\mathrm{V}$ shows the reported adverse reactions. The

TABLE III-Mean (SD) serum potassium and urate concentrations and urinary sodium excretion at weeks 0 and 8 by dose of cyclopenthiazide

\begin{tabular}{|c|c|c|c|c|c|c|}
\hline \multirow{2}{*}{$\begin{array}{l}\text { Dose of } \\
\text { cyclopenthiazide } \\
(\mu \mathrm{g})\end{array}$} & \multicolumn{2}{|c|}{ Potassium (mmol/l) } & \multicolumn{2}{|c|}{ Urate $(\mathrm{mmol} / \mathrm{l}$} & \multicolumn{2}{|c|}{ Urinary sodium $(\mathrm{mmol} / 24 \mathrm{~h})$} \\
\hline & Week 0 & Week 8 & Week 0 & Week 8 & Week 0 & Week 8 \\
\hline Placebo $(n=12)$ & $4.2(0.4)$ & $4 \cdot 1(0.4)$ & $0.34(0.07)$ & $0.31(0.09)$ & $165(44)$ & $162(48)$ \\
\hline $50(n=13)$ & $4 \cdot 1(0.4)$ & $4 \cdot 2(0.4)$ & $0.36(0.09)$ & $0.34(0.07)$ & $162(56)$ & $167(56)$ \\
\hline $125(n=15)$ & $4.2(0.3)$ & $4 \cdot 0(0.3)$ & $0.33(0.07)$ & $0.33(0.08)$ & $160(48)$ & $166(57)$ \\
\hline $500(n=13)$ & $4 \cdot 2(0 \cdot 4)$ & $3.6(0.3)$ & $0.32(0.06)$ & $0.38(0.07)^{\star}$ & $126(61)$ & $159(65)$ \\
\hline
\end{tabular}

${ }^{\star} \mathrm{p}<0.05$ as compared with placebo.

TABLE IV-Mean (SD) plasma renin activities (nmol angiotensin I/l) h) at weeks 0 and 8 by dose of cyclopenthiazide

\begin{tabular}{ccccc}
\hline & & \multicolumn{3}{c}{ Dose of cyclopenthiazide $(\mu \mathrm{g})$} \\
\cline { 3 - 5 } Week of treatment & Placebo & 50 & 125 & 500 \\
\hline 0 & $0.9(0.5)$ & $0.8(0.4)$ & $1 \cdot 2(0.6)$ & $1.8(1 \cdot 3)$ \\
8 & $1.1(0.5)$ & $0.9(0.6)$ & $1.2(0.8)$ & $5.4(4 \cdot 1)^{\star}$ \\
\hline
\end{tabular}

${ }^{\star} \mathrm{p}<0.05$ as compared with placebo and 50 and $125 \mu \mathrm{g}$ cyclopenthiazide.

TABLE V-Reported adverse reactions during treatment. Values are numbers of patients 太

\begin{tabular}{lcccc}
\hline & \multicolumn{4}{c}{ Dose of cyclopenthiazide $(\mu \mathrm{g})$} \\
\cline { 3 - 5 } & $\begin{array}{l}\text { Placebo } \\
(\mathrm{n}=12)\end{array}$ & $\begin{array}{c}50 \\
(\mathrm{n}=13)\end{array}$ & $\begin{array}{c}125 \\
(\mathrm{n}=15)\end{array}$ & $\begin{array}{c}500 \\
(\mathrm{n}=13)\end{array}$ \\
\hline $\begin{array}{l}\text { Ndverse reaction } \\
\begin{array}{l}\text { Diarrea } \\
\text { Constipation }\end{array}\end{array}$ & 1 & 3 & 3 & 1 \\
$\begin{array}{l}\text { Rashes } \\
\text { Headache }\end{array}$ & 1 & 1 & 2 & \\
$\begin{array}{l}\text { Ringing in ears } \\
\text { Impotence }\end{array}$ & 1 & 4 & 2 & 4 \\
Joint pains & 1 & & & \\
$\begin{array}{l}\text { Dizziness } \\
\text { Tiredness }\end{array}$ & 1 & 1 & 2 & 1 \\
More frequent micturition & 2 & 2 & 2 & 1 \\
\hline Total & 2 & 13 & 13 & 8 \\
\hline
\end{tabular}

^Some patients had multiple complaints.

incidence of side effects was not different between the four groups, and the side effects were generally minor as no patient receiving treatment with cyclopenthiazide or placebo failed to complete the study. Interestingly, two patients who had had treatment with $200 \mathrm{mg}$ labetalol daily to control their blood pressure experienced headache, tremor, restlessness, anxiety, and palpitations for 2-3 days on discontinuing treatment with labetalol. These withdrawal symptoms have been seen with abrupt cessation of both selective and nonselective $\beta$ blockers in patients with hypertension. ${ }^{22}{ }^{23}$ Compliance with the treatment regimen as assessed by counting of pills was more than $90 \%$ for all patients.

\section{Discussion}

Our results show that in a subgroup of patients with mild essential hypertension both the 125 and 500 $\mu \mathrm{g}$ preparations of cyclopenthiazide produced clinically relevant decrements in blood pressure averaging $20 / 11 \mathrm{~mm} \mathrm{Hg}$ and $24 / 10 \mathrm{~mm} \mathrm{Hg}$, respectively, after eight weeks of treatment. These reductions in blood pressure are in a range previously documented for thiazide diuretics. ${ }^{24}$ No useful antihypertensive activity was apparent with the $50 \mu \mathrm{g}$ dose of cyclopenthiazide at any stage during the trial.

Increasing the dose of chlorthalidone, a diuretic like the thiazides above $25 \mathrm{mg}$ /day has been shown to confer little added hypotensive effect. ${ }^{25} 26$ Materson $e t$ al examined a lower range of doses of chlorthalidone in their between patient study. ${ }^{27}$ Each group was randomly assigned to receive $12 \cdot 5,25,50$, or $75 \mathrm{mg}$ chlorthalidone or matching placebo for 12 weeks. All doses lowered blood pressure, and no significant difference was detected in the hypotensive response to treatment in any group, although the lower dose was regarded as being slightly less efficacious than the other treatments. A later trial showed, however, a decrease in mean blood pressure of $25 / 13 \mathrm{~mm} \mathrm{Hg}$ with $12.5 \mathrm{mg}$ chlorthalidone in patients with hypertension who were treated for three months. ${ }^{28} \mathrm{~A}$ similar pattern has been defined for hydrochlorothiazide, with no added antihypertensive activity seen on increasing the dose from 12.5 to $50 \mathrm{mg}$ daily. ${ }^{29}$ From these data it could be argued that the lowest amount of a thiazide diuretic capable of producing a clinically relevant antihypertensive effect remains to be established as the dose response curve was already flat at the lower doses. Our results clearly define the lower end of the antihypertensive dose response curve for cyclopenthiazide.

The biochemical abnormalities produced by the 500 $\mu \mathrm{g}$ preparation of cyclopenthiazide reflect the well known changes incurred and accepted by doctors when these drugs are used at conventional doses. The decline in serum potassium concentration occurred early, being largely complete by four weeks, with little further effect seen later. This finding agrees with the observations of other workers. ${ }^{30}$ Changes in serum potassium and urate concentrations related to dose of drug have been documented when thiazide diuretics were used to control hypertension. ${ }^{31}{ }^{32}$ In a comparative low dose study using $12.5 \mathrm{mg}$ hydrochlorothiazide and $2.5 \mathrm{mg}$ bendrofluazide in patients with hypertension no change was noted in the serum potassium concentration, although both doses significantly raised serum urate concentration. ${ }^{32}$ Debate continues about the effect of these asymptomatic biochemical abnormalities induced by drugs and their potential threat to health. ${ }^{33-35}$ Our findings suggest that lower doses of cyclopenthiazide will cause less upset to the biochemical profile.

No relation was noted between the dose of cyclopenthiazide given and 24 hour urinary sodium excretion during the trial. The $500 \mu \mathrm{g}$ preparation produced a noticeable increase in plasma renin activity that was not obvious with the other doses or placebo. Few studies have examined the effect of low dose treatment with diuretic drugs on plasma renin activity in essential hypertension. When it has been measured the amount of drug prescribed was sufficient to stimulate renin secretion. ${ }^{25}{ }^{36}$ To our knowledge, this is the first time a clinically relevant antihypertensive effect has been documented with a thiazide diuretic, without any concomitant increase in plasma renin activity being evident. The mechanisms whereby thiazides increase renin activity are complex and incompletely understood, ${ }^{37}$ but the production of a negative sodium balance and constriction of plasma and extracellular fluid volumes undoubtedly have an important role. ${ }^{38}$

The initial and longer term antihypertensive mechanism of action of thiazide diuretics are known to differ. ${ }^{39}$ Some authorities suggest that the long term antihypertensive effect is seen with continued doses of drug below the threshold required for effective saluresis. ${ }^{40}$ Our results seem to lend further support for this concept. Early work with cyclopenthiazide in 
normal volunteers suggested that $125 \mu \mathrm{g}$ of the drug had a small, but measurable, natriuretic effect. As cyclopenthiazide is estimated to be 70 times more potent than hydrochlorothiazide in promoting natriuresis, ${ }^{41}$ about $9 \mathrm{mg}$ of hydrochlorothiazide would produce an equivalent natriuretic response.

The finding that one quarter of patients were normotensive after discontinuing treatment for four weeks requires explanation. This rate certainly seems higher than that found in comparable studies of mild hypertension. ${ }^{27} 29$ Measuring the blood pressure at home may have contributed to these findings. It is recognised that blood pressure readings taken at home are generally lower than and more closely related to average 24 hour ambulatory pressure than measurements taken in the clinic. ${ }^{42}{ }^{43}$ This may be important as cardiovascular complications in essential hypertension are determined by the average value of arterial pressure throughout the day. ${ }^{445}$ Although a four week washout period would be standard in trials of this nature, it may be insufficient to ensure that no antihypertensive effect induced by drug treatment persists, especially if patients had been taking a $\beta$ blocker ${ }^{29}$ or chlorthalidone..$^{28}$ In our study 12 patients had been previously treated with a $\beta$ blocker and none had received chlorthalidone. In addition, in many patients treatment was started before recommendations about measuring blood pressure became widely appreciated. ${ }^{46}$ This may have resulted in the inappropriate prescribing of antihypertensive treatment at the first medical consultation. Whatever the reasons these data highlight that care and accuracy in monitoring blood pressure is required in mild essential hypertension to avoid instituting unnecessary treatment. We documented unwanted side effects, which were few, and found no relation between the dose of cyclopenthiazide and the prevalence of adverse effects.

Our results indicate that the $125 \mu \mathrm{g}$ preparation of cyclopenthiazide has a place in treating mild essential hypertension. Furthermore, they confirm previous observations that selecting the lowest possible dose of diuretic for each patient can successfully decrease blood pressure with minimal upset to the metabolic profile. This policy would be especially prudent for elderly patients, who are particularly susceptible to the pharmacological actions of conventional doses of diuretic drugs. ${ }^{47}$

We thank all the general practitioners who helped with recruitment for this study. We thank Napp Research Centre for supplying the cyclopenthiazide and placebo preparations, $\mathrm{Mr}$ John McKellar for statistical advice, and Miss Anne Ravenscroft for help in organising the trial.

1 Hollander W, Wilkins RW. Chlorothiazide: a new type of drug for the We of arterial hypertension. Boston Medical Quarterly 1957;8:68-75. Medical Research Council Working Party. MRC trial of treatment of mild hypertension: principal results. Br Med f 1985;291:97-104.

3 Hypertension Detection and Follow-up Program Cooperative Group. Fiveyear findings of the Hypertension Detection and Follow-up Program. I. Reduction in mortality of persons with high blood pressure, including mild hypertension. JAMA 1979;242:2562-71.

4 Management Committee of the Australian Therapuetic Trial in Mild Hypertension. Report. Lancet 1980; i:1261-7.

5 Helgeland A. Treatment of mild hypertension: a five year controlled drug trial. The Oslo Study. Am $\mathcal{F}$ Med 1980;69:725-32.
tritel

trial. The Oslo Study. Am f Med 1980;69:725-32.
6 Shah S, Khatri I, Fries ED. Mechanism of antihypertensive effect of thiazide diuretics. Am Heart 7 1978;95:611-8.

7 Cranston WI, Juel-Jensen BE, Semmence AM, Handfield Jones RPC, Forbes JA, Mutch LMN. Effects of oral diuretics on raised arterial pressure. Lancet 1963;ii:966-70.

8 Weber MA, Lopez-Ovejero JA, Drayer JI, Case DB, Laragh JH. Renin reactivity as a determinant of responsiveness to antihypertensive treatment. Arch Intern Med 1977;137:284-9.

9 Vaughan DE Jr, Carey RM, Peach MJ, Ackerly JA, Ayers CR. The renin response to diuretic therapy. A limitation of antihypertensive potential. Circ Res 1978;42:376-81.
10 Leonetti G, Terzoli L, Sala C, Bianchini C, Sernesi L, Zanchetti A. Relationship between the hypotensive and renin-stimulating actions of diuretic therapy in hypertensive patients. Clinical Science and Molecular Medicine 1978;55:307-9S.

11 Kaplan NM. Problems with the use of diuretics in the treatment of hypertension. Am J Nephrol 1986;6:1-5.

12 Knochel JP. Diuretic-induced hypokalemia. Am f Med 1984;77:18-27.

13 Multiple Risk Factor Intervention Trial Research Group. Mutiple Risk Facto Intervention Trial. Risk factor changes and mortality results. FAMA 1982;248:1465-77.

14 The Hypertension Detection and Follow-up Program Co-operative Research Group. The effect of antihypertensive drug treatment on mortality in the presence of resting electrocardiographic abnormalities at baseline: the HDFP experience. Circulation 1984;70:966-1002.

15 Moser M. Clinical trials, diuretics, and the management of mild hypertension. Arch Intern Med 1984;144:789-92.

16 Degnbol B, Dorph S, Marner T. The effect of different diuretics on elevated blood pressure and serum potassium. Acta Med Scand 1973;193:407-10.

17 Bengtsson C, Johnsson G, Sannerstedt R, Werko L. Effect of different doses of chlorthalidone on blood pressure, serum potassium, and serum urate. BrMed f 1975; i: 197.9.

18 Webster J, Newnham D, Petrie JC, Lovell HG. Influence of arm position on measurement of blood pressure. Br Med f 1984;288:1574-5.

19 Haber E, Koerner T, Page LB, Kliman B, Purnode A. Application of a radioimmunoassay for angiotensin I to the physiologic measurements of plasma renin activity in normal subjects. F Clin Endocrinol 1969;29:1349-55.

20 Colton T. Statistics in medicine. Boston: Little, Brown, and Co, 1974:144-5.

21 Armitage P. Statistical methods in medical research. Oxford: Blackwell, 1971: 205-7.

22 Pedersen OL. Comparison of metoprolol and hydrochlorothiazide as antihypertensive agents. Eur f Clin Pharmacol 1976;10:381-5.

23 Rangno RE, Langlois $S$. Comparison of withdrawal phenomena after propranolol, metoprolol, and pindolol. Am Heart 7 1982;104:473-8.

4 Ram CVS. Diuretics in the management of hypertension. Postgrad Med 1982;71:155-68.

25 Carney S, Gillies AI, Morgan T. Optimal dose of a thiazide diuretic. Med F A ust 1976;2:692-3.

26 Russell JG, Mayhew SR, Humphries IS. Chlorthalidone in mild hypertensiondose response relationship. Eur f Clin Pharmacol 1981;20:407-11

27 Materson BJ, Oster JR, Michael UF, et al. Dose response to chlorthalidone treatment in previously untreated hypertension. Clin Pharmacol Ther 1977;24:192-8.

28 Korduner I, Kabin I, Hagbarth G. Low-dose chlorthalidone treatment in previously untreated hypertension. Current Therapeutic Research 1981;29:208-15.

29 Berglund G, Andersson O. Low doses of hydrochlorothiazide in hypertension. Antihypertensive and metabolic effects. Eur $f$ Clin Pharmacol 1976;10:177-82.

30 Morgan DB, Davidson C. Hypokalaemia and diuretics: an analysis of publications. BrMed f 1980;280:905-8.

31 Tweddale MG, Ogilvie RI, Ruedy J. Antihypertensive and biochemical effects of chlorthalidone. Clin Pharmacol Ther 1977;22:519-27.

32 Multicentre Study Group. Hydrochlorothiazide and bendroflumethiazide in low doses-a comparative trial. Acta Pharmacol Toxicol (Copenh) 1984;54 (suppl I):47-51.

3 Papademetriou V, Fletcher R, Khatri IM, Fries ED. Diuretic-induced hypokalemia in uncomplicated systemic hypertension. Effect of plasma potassium correction on cardiac arrhythmias. Am $\mathcal{J}$ Cardiol 1983;52: 1017-22.

34 Boyd JC, Bruns DE, DiMarco JP, Sugg KW, Willis MR. Relationship of potassium and magnesium concentrations in serum to cardiac arrhythmias. Clin Chem 1984;30:754-7.

35 Hollifield JW. Thiazide treatment of hypertension. Effects of thiazide diuretics on serum potassium, magnesium, and ventricular ectopy. Am 7 Med 1986;80:8-12.

36 Lammintausta $R$, Lammintausta $\mathrm{K}$. The renin-aldosterone system in lowdose chlorothiazide treatment of hypertensive subjects. Int 7 Clin Pharmacol Ther Toxicol 1980;18:329-31.

37 Guthrie GP Jr, Genest J, Kuchel O. Renin and the therapy of hypertension. Annu Rev Pharmacol Toxicol 1976;16:287-308.

38 Keeton TK, Campbell WB. The pharmacologic alteration of renin release. Pharmacol Rev 1981;31:81-227.

39 Fries ED. How diuretics lower blood pressure. Am Heart f 1983;106: 185-7.

40 Lant AF. Evaluation of diuretics and ACE inhibitors, their renal and antihypertensive actions-parallels and contrasts. $\mathrm{Br} \mathrm{J}$ Clin Pharmacol 1987;23:27-41S

41 Dettli L, Spring P. Comparative pharmacological investigation of a new salidiuretic (cyclopenthiazide) in healthy man. A methodical contribution to the testing of diuretics. Zietschrift für die gesamte Experiment alle Medizin Einschliesslich Experimenteller Chirurgie 1960;134:310-22.

42 Kleinert HD, Harshfield GA, Pickering TA, et al What is the value of home blood pressure measurement in patients with mild hypertension? blood pressure measure
Hypertension $1984 ; 6: 574-8$.

43 Schmidt GR, Pitterle ME, Schuna AA. Home blood pressure readings in clinical hypertension research. Clin Pharmacol 1986;5:917-20.

44 Sokolow M, Werdegar D, Kain HK, Hinman AT. Relationship between level of blood pressure measured casually and by portable recorders and severity of complications in essential hypertension. Circulation 1966;34: 279-98.

45 Ibrahim MM, Tarazi RC, Dustan HP, Gifford RW. Electrocardiogram in evaluation of resistance to antihypertensive therapy. Arch Intern Med 1977; 137:1125-9.

46 Beevers DG. Blood pressures that fall on rechecking. BrMed f 1982;284:71-2.

47 Smith WE, Steele TH. Avoiding diuretic-related complications in older patients. Geriatrics 1983;38:117-24.

(Accepted 12 April 1988) 